\title{
Considerations in the integration of eye care into leprosy care services
}

\author{
P COURTRIGHT* $\ddagger \&$ SUSAN LEWALLEN $\dagger$ \\ *International Centre for Eye Health, 27-29 Cayton Street, London \\ ECIV 9EJ; and †International Eye Foundation, PO Box 2273,

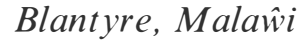

Accepted for publication 23 September 1991

\begin{abstract}
Summary Little attention has been directed to the development, management and evaluation of eye care programmes for leprosy patients. This paper examines when an eye care programme for leprosy patients is needed, methods for integrating eye care into leprosy control programmes and lists of available ocular leprosy teaching materials.
\end{abstract}

\section{Introduction}

Leprosy control programmes began as vertical programmes and still exist as such today in many places. Vertical health programmes often result in a lack of comprehensive care for the patient, and eye problems in leprosy patients have often been neglected. Leprosy patients with visual loss form a particularly disadvantaged group because of other disabilities from the disease and the difficulties and delay in receiving appropriate eye care. In recent years ocular leprosy has been the focus of increasing scientific investigation. Nevertheless, little attention has been directed to the development, management, and evaluation of eye care programmes for leprosy patients.'

Ocular complications of leprosy often develop slowly; minor pathology is frequently overlooked or neglected with the result that serious problems develop. However, many of the blinding complications of leprosy are preventable or treatable by simple means and at low cost.

\section{When is an eye care programme needed?}

How should a programme manager determine if an eye care programme is needed? Population-based surveys give the most accurate information, ${ }^{2}$ but are costly. A more practical approach may be to review the clinical status of patients in a leprosy control

$\ddagger$ Reprints: Professor G J Johnson, International Centre for Eye Health, 27-29 Cayton Street, London ECIV 9EJ. 
programme. An answer of 'yes' to any of the following indicates that there may be a significant prevalence of eye disease.

Is there a large number (or proportion) of leprosy patients with multibacillary disease?

2 Is there a large number (or proportion) of 'cured' leprosy patients (multibacillary or paucibacillary) over 50 years of age or with a period of over 25 years since initial diagnosis?

3 Is the average period of time between onset and diagnosis over 5 years among most newly diagnosed patients or, do many newly diagnosed patients have moderate to severe (grade 2-3) disabilities?

The above criteria are based on the assumption that patients who receive a complete course of multidrug therapy are not likely to develop potentially blinding ocular pathology. Anecdotal reports suggest this may not be the case. Leprosy control programmes that discharge leprosy patients with inadequate follow-up after completion of multidrug therapy will be likely to place many 'cured' leprosy patients beyond the supervision necessary to avoid further eye complications and blindness. Nevertheless, until more information is available, attention to ocular disease should be provided at least in those settings described in 1-3 above.

\section{Integration of eye care into leprosy control programmes}

Eye care in developing countries is usually available only in tertiary care facilities. A few leprosy centres do provide ophthalmology services. Most of these institutions have an ophthalmologist whose primary responsibility is the ocular treatment of leprosy patients. While high quality tertiary care is available, patients self-present only, follow-up is variable, and there is no relationship between leprosy control activities in the field and ocular care in the institution. The challenge is to devise a system that integrates eye care activities into leprosy control programmes in the field to provide a comprehensive eye care programme.

In a number of developing countries paramedical eye workers have been shown to be an effective group capable of providing primary eye care; they form an essential segment of the eye care infrastructure in ophthalmologist-poor areas of Africa and Asia. ${ }^{3-7}$ In the past few years some attempts have been made to develop programmes utilizing leprosy paramedical workers as the front line for ocular care for their patients. ${ }^{8}$ The fact that most pathology in ocular leprosy is in the anterior segment of the eye makes it particularly appropriate for detection by leprosy health workers with minimal training and equipment. Patient education in ocular complications of leprosy can be integrated into existing disability prevention programmes and be a component of a health worker's regular patient visits.

Training of primary health workers provides basic technical skills but is only one component of a comprehensive eye care programme. Primary health workers must be supported by an appropriate and efficient referral system in order to gain the confidence of the patient. Adequate examination equipment and drugs are also required to maintain a successful programme. To this end, political and administrative support of eye work within the leprosy programme is mandatory. To establish an adequate referral system collaboration between leprosy control programmes and general eye care services is almost 
always essential. Additional and specific education of the ophthalmology community about leprosy may be necessary to achieve this; only in the special settings where a 'leprosy ophthalmologist' is found can the general eye care services be disregarded by the leprosy programme. Collaboration may be furthered by the establishment of a consultative group composed of both leprosy control and ophthalmology personnel. This group may establish tertiary services for leprosy patients at general eye care facilities, conduct seminars on eye care for leprosy health workers and hospital staff, and evaluate programmes in eye care.

\section{Conclusion}

An eye care programme for leprosy control programmes in developing countries should be affordable to the country concerned and acceptable and accessible to all the leprosy patients. It should comprise various levels of health care with a well-structured referral chain allowing transferrals from the paramedical level through secondary services up to tertiary care for those who need it. Teaching materials and curriculums available for both the health worker and the trainer/ophthalmologist are listed in Table 1. There are certain aspects of leprosy control programmes that facilitate the integration of eye care into the programmes. There is already a system of paramedical workers established in the field and the additional training for them to learn primary prevention of eye disease is not great. Training paramedical workers, however, is only the first step. They must be supported in their duties by the administrators of the leprosy control programme and by a referral

Table 1. Ocular leprosy teaching materials

\begin{tabular}{|c|c|}
\hline Title and author & Source \\
\hline $\begin{array}{l}\text { Care of the eye in Hansen's disease } \\
\text { (Brand, } \mathrm{M})\end{array}$ & $\begin{array}{l}\text { The Star, Gillis Long Center, Carville, LA 70721, } \\
\text { USA }\end{array}$ \\
\hline $\begin{array}{l}\text { Leprosy of the eye: A general outline } \\
\text { (Joffrion VC, Brand } \mathrm{M} \text { ) }\end{array}$ & Gillis Long Center, Carville, LA 70721, USA \\
\hline $\begin{array}{l}\text { Eye care in Hansen's disease: A screening tool for } \\
\text { nurses } \\
\text { (Brand, M, Courtright P, Demarest V) }\end{array}$ & Gillis Long Centre, Carville, LA 70721, USA \\
\hline Slide set on ocular leprosy & $\begin{array}{l}\text { American Leprosy Missions, } 1 \text { ALM Way, } \\
\text { Greenville, SC 29601, USA }\end{array}$ \\
\hline $\begin{array}{l}\text { Video: } \\
1 \text { The red eye } \\
2 \text { Eye in leprosy } \\
3 \text { Keep blinking }\end{array}$ & $\begin{array}{l}\text { Schieffelin Leprosy Research \& Training Centre, } \\
\text { SLR Sanatorium, P.O. PIN } 632 \text { 106, N. Arcot, } \\
\text { Tamil Nadu, India }\end{array}$ \\
\hline $\begin{array}{l}\text { Video: Health workers and blindness prevention in } \\
\text { leprosy }\end{array}$ & $\begin{array}{l}\text { Project ORBIS, } 330 \text { W. 42nd Street, New York, NY } \\
\text { 10036, USA }\end{array}$ \\
\hline $\begin{array}{l}\text { Guide to ocular leprosy for health workers } \\
\text { (Courtright } \mathrm{P}, \text { Lewallen } \mathrm{S} \text { ) }\end{array}$ & $\begin{array}{l}\text { German Leprosy Relief Association, Postfach } \\
\text { 110462, D-8700 Wurzburg, } 11 \text { Germany (available } \\
\text { 1992) }\end{array}$ \\
\hline $\begin{array}{l}\text { Training health workers to recognize, treat, refer and } \\
\text { educate patients about ocular leprosy } \\
\text { (Courtright } \mathrm{P}, \text { Lewallen } \mathrm{S})\end{array}$ & $\begin{array}{l}\text { German Leprosy Relief Association, Postfach } \\
\text { 110462, D-8700 Wurzburg, } 11 \text { Germany (available } \\
\text { 1992) }\end{array}$ \\
\hline
\end{tabular}




\begin{tabular}{|c|c|}
\hline & Role: \\
\hline & Teaching clinical officers or ophthalmic medical assistants \\
\hline Ophthalmologist & Tertiary eye referrals \\
\hline 4 & $\begin{array}{l}\text { Intraocular surgery: } \\
\text { cataract extraction } \\
\text { glaucoma surgery }\end{array}$ \\
\hline & Role*: \\
\hline & Teaching paramedical workers \\
\hline $\begin{array}{c}\text { Leprosy clinical officer } \\
\text { or }\end{array}$ & $\begin{array}{l}\text { Recognize and treat or refer: } \\
\text { corneal abnormality } \\
\text { conjunctival injection } \\
\text { pupil abnormality }\end{array}$ \\
\hline ophthalmic medical assistant & $\begin{array}{l}\text { Treat: } \\
\text { lagophthalmos/ectropion } \\
\text { trichiasis }\end{array}$ \\
\hline & Role: \\
\hline & $\begin{array}{l}\text { Recognize: } \\
\text { decreased vision } \\
\text { lagophthalmos/ectropion } \\
\text { trichiasis } \\
\text { corneal abnormality } \\
\text { conjunctival injection } \\
\text { pupil abnormality }\end{array}$ \\
\hline Paramedical worker & $\begin{array}{l}\text { Treat and refer: } \\
\text { corneal exposure } \\
\text { acute uveitis } \\
\text { chronic iritis } \\
\text { conjunctival injection }\end{array}$ \\
\hline & $\begin{array}{l}\text { Refer: } \\
\text { cataract } \\
\text { unexplained vision loss } \\
\text { Patient education }\end{array}$ \\
\hline
\end{tabular}

* To be fulfilled by an ophthalmologist in the absence of an eye-trained leprosy clinical officer or ophthalmic medical assistant.

Figure 1. Hierarchy of eye care services for leprosy patients.

structure which includes the ophthalmology community. Ocular disability prevention can be integrated into existing leprosy control services through collaboration between leprosy paramedical workers, leprosy clinical officers, and ophthalmologists (Figure 1).

\section{Acknowledgments}

Integrating eye care services into leprosy control programmes has been supported by the 
German Leprosy Relief Association, American Leprosy Missions, and Project ORBIS. The authors gratefully acknowledge their support.

\section{References}

1 Courtright P, Johnson GJ. Prevention of blindness in leprosy. International Centre for Eye Health, London. 1988.

2 Courtright P. Defining the magnitude of ocular leprosy: Problems of methodology. Int J Lepr, 1988; 56: 566573.

3 Sutter E, Foster A, Francis V. Hanyane: a village struggles for eye health. Macmillan Publishers (London) 1989.

${ }^{4}$ Sheffield VM. Primary eye care at various levels in Kenya. In Acta XXIV International Congress of Ophthalmology. Henkind P (ed) American Academy of Ophthalmology: J. P. Lippincott, Philadelphia, 1983.

5 World Health Organization. Blindness prevention: training auxiliary personnel in eye care. WHO Chronicle, 1980; 34: 332-5.

6 Sutter E. Training of eye care workers and their integration in Gazankulu's comprehensive health services. Soc Sci Med, 1983; 17: 1809-12.

7 Chana HS. Eye care programmes in developing countries. Majestic Printing (Nairobi) 1989.

${ }^{8}$ Courtright $\mathrm{P}$, Lee HS, Lewallen S. Training for primary eye care in leprosy. Bull WHO, 1990; 68: 347-51. 